\title{
Gas-Phase Ion-Molecule Reactions of Transition Metal Complexes: The Effect of Different Coordination Spheres on Complex Reactivity
}

\author{
Marianny Y. Combariza and Richard W. Vachet \\ Department of Chemistry, University of Massachusetts, Amherst, Massachusetts, USA
}

\begin{abstract}
Using a modified quadrupole ion trap mass spectrometer, a series of metal complex ions have been reacted with acetonitrile in the gas phase. Careful control of the coordination number and the type of coordinating functionality in diethylenetriamine-substituted ligands enable the effects of the coordination sphere on metal complex reactivity to be examined. The association reaction kinetics of acetonitrile with these pentacoordinate complexes are followed in order to obtain information about the starting complexes and the reaction dynamics. The kinetics and thermodynamics of acetonitrile addition to the metal complex ions are strongly affected by the chemical environment around the metal center such that significant differences in reactivity are observed for $\mathrm{Co}(\mathrm{II})$ and $\mathrm{Cu}(\mathrm{II})$ complexes with various coordination spheres. When thiophene, furan, or benzene moieties are present in the coordination sphere of the complex, addition of two acetonitrile molecules is readily observed. In contrast, ligands with better $\sigma$ donors react mainly to add one acetonitrile molecule. Among the ligands with good $\sigma$ donors, a clear trend in reactivity is observed in which complexes with nitrogen-containing ligands are the least reactive, sulfur-containing complexes are more reactive, and oxygen-containing complexes are the most reactive. In general, equilibrium and reaction rate constants seem to be consistent with the hard and soft acid and base (HSAB) principle. Interestingly, the presence of certain groups (e.g., pyridine and imidazole) in the coordination sphere clearly can change the acid character of the metal as seen by their effect on the binding properties of other functional groups in the same ligand. Finally, we conclude that because complexes with different coordination spheres react to noticeably different extents, ion-molecule (I-M) reactions may be potentially useful for obtaining coordination structure information for transition metal complexes. (J Am Soc Mass Spectrom 2002, 13, 813-825) (c) 2002 American Society for Mass Spectrometry
\end{abstract}

$\mathrm{I}$ n the gas phase, ion-neutral interactions are not affected by factors common to solution chemistry such as ion pairing, solvation, and inter-molecular interactions. Because of this, ion molecule (I-M) experiments can be used to study the intrinsic properties of charged species and their chemical reactions [1-4]. Along with collision-induced dissociation (CID), I-M reactions can also be tools that provide structural information in a mass spectrometric experiment [5-7]. I-M reactions are advantageous as structural probes for several reasons. They are highly selective, efficient, and fast. They are also relatively simple, and there are numerous possible combinations of ions and neutrals that can be analytically useful [7-9]. Finally, I-M reac-

Published online May 20, 2002

Address reprint requests to Dr. R. W. Vachet, Department of Chemistry, University of Massachusetts, 710 North Pleasant Street, 701 Lederle Graduate Research Tower, Amherst, MA 01003, USA. E-mail: rwvachet@ chem.umass.edu tions are inherently softer than CID methods, which require "heating up" ions to induce dissociation.

CID of metal complexes has been studied by several investigators but mainly in order to determine the binding strengths of ligands to monovalent metals [10]. Studying the dissociation dynamics of metal complex ions from a structural elucidation standpoint, however, has received less attention. Brodbelt and co-workers have studied the dissociation patterns of polyether, crown ether, and polypyridyl complexes of singly- [11, 12] and doubly-charged transition metal ions [13, 14]. Details about the effect of ligand flexibility and metal type on dissociation pathways has been gathered from these studies. Additional work has also applied CID to other transition metal complexes [15-26]. In general, these studies reveal that rearrangement reactions involving the loss of small neutrals from large ligands or the loss of intact ligands from multi-ligated metal ions are typical. Unfortunately, neither provides much in- 
sight into the coordination sphere since they often do not reveal whether the groups lost were coordinated to the metal or not.

Better evidence of the utility of CID to gather coordination structure information from metal complexes can be seen in the investigations of transition metalpeptide complexes [27-34]. The main premise in these studies is that the metal ion induces dissociations adjacent to its binding site. In complexes containing cysteine and histidine, the preferred dissociation pathways are the ones along the peptide backbone adjacent to the coordinating side chain $[29,30,32,34]$. The location of the other binding sites in histidine and cysteine-containing peptides, however, are more difficult to determine by CID. Tyrosine and phenylalanine residues are also observed to direct metal-complex dissociations, apparently through the interaction of the aromatic $\pi$-system with the metal [31]. In metal-peptide complexes that do not contain strongly coordinating amino acids, CID results suggest that transition metals bind through deprotonated backbone amides [27, 28]. While in each of these cases correlations between gasphase binding and solution-phase binding of transition metal-peptide complexes can be inferred from the CID spectra, very little evidence has been presented to suggest coordination sphere structure can be determined a priori. At this point, elucidation of metalligand connectivity using CID alone seems to be limited ultimately by the inability to determine whether a fragment lost during CID was initially coordinated to the metal or not. Thus, another (or complementary) means of analyzing the ligation of metal complexes by mass spectrometry (MS) would be useful. Because of their inherent gentleness and other positive attributes, I-M reactions may effectively provide coordination structure information. In addition, I-M experiments could be used in conjunction with CID methods, affording a powerful combination for obtaining gas-phase structure.

Gas-phase I-M reactions of metal ions with small organic molecules have been extensively studied [3537]. Research in this area has focused predominantly on the interactions of monovalent transition metals ions with small alkanes, alkenes, ethers, ammonia, and water because these systems are good models for understanding the fundamentals of catalytic processes [36, 38-40]. Some research also has been extended to study the reactions of partially ligated monovalent metal ions [41]. Despite the tremendous insight into $\mathrm{C}-\mathrm{H}$ and $\mathrm{C}-\mathrm{C}$ bond activation gained from these studies, the significant majority of the gas-phase data comes from complexes in which the metal is in an oxidation state of +1 . The development of electrospray (ESI) and other ionization techniques [42, 43], however, now allows the study of complexes with metals in higher oxidation states, which are usually more relevant to solutionphase metal chemistry. These techniques have enabled detailed studies of divalent metal solvation by water and a variety of other ligands [44-49] as well as charge transfer processes in coordination complexes [50,51].
Techniques like ESI have also enabled recent I-M reaction studies of divalent metal-ligand complexes [52-56]. These studies reveal that metal-ligand complexes have unique reactivity that depends on their level of coordinative saturation, suggesting that I-M reactions may be able to provide useful structural information for metal complexes. In a couple of these studies, Vachet et al. observed that the coordination number of transition metal complexes could be established by "titrating" the complex with specific reagent ligands $[54,56]$. The general idea is that complexes of first-row transition metals will be reactive to an extent that depends on their degree of coordinative unsaturation. In the gas-phase, first-row transition metal complexes with coordination numbers less than six react until they obtain a coordination number of six with the exception of $\mathrm{Cu}$ (II) complexes, which are resistant to the addition of a sixth ligand in the gas-phase because of the effects of Jahn-Teller distortion [54]. In this way, the coordination number of a metal complex can be determined from the increase in the $\mathrm{m} / \mathrm{z}$ ratio of the monitored species after a reaction with a reagent ligand.

In the present work we expand on the idea that I-M reactions can provide structural information about a metal's coordination sphere by following the association reactions of acetonitrile with $\mathrm{Co}$ (II) and $\mathrm{Cu}$ (II) complexes of model ligands. Our premise is that the reactivity of gas-phase metal complex ions will depend on factors such as the metal's electronic structure, the ligand field around the metal, the complex's geometry, and the degree of coordinative unsaturation. I-M reactions should then be sensitive to differences in coordination structure such that they might be used to distinguish these variations and perhaps provide a means of structurally characterizing metal complexes. This work presents our initial studies in which we explore the effect of various ligand fields on the I-M reactivity of metal complexes. Ultimately, one of our goals is to develop a MS-based technique to structurally characterize metal complexes using I-M reactions.

\section{Experimental}

All experiments are carried out in a Bruker Esquire-LC quadrupole ion trap mass spectrometer (Billerica, MA) modified to allow the introduction of reagent gases into the vacuum system. The helium inlet line on the Esquire-LC has been replaced by a three-valve leaking system. The addition of reagent gases and helium to the vacuum system is controlled by individual precision leak valves (MDC Vacuum Products Corp., Hayward, CA). Acetonitrile $(99.5 \%$, Aldrich) is placed in a small glass ampoule connected to one of the precision leak valves, and the air in the sample is evacuated by several freeze/pump/thaw cycles. Ammonia (99.99\%, Matheson Tri-gas, Parsippany, NJ) is also introduced into the vacuum system via one of the precision leak valves and is used to calibrate the pressure in the mass spectrometer (vide infra). 


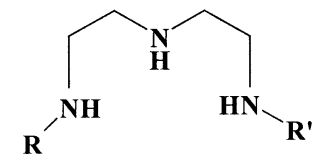

DIEN-R-R'

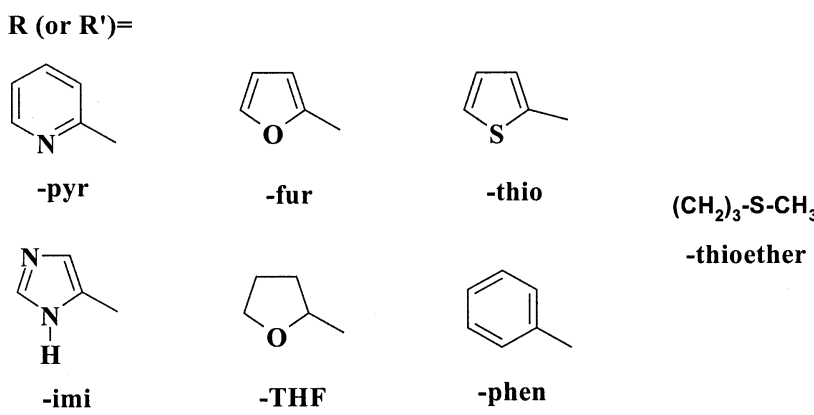

Figure 1. Structures of the ligands used in this study.

A capacitance manometer (Kurt J. Lesker Co., Clairton, $\mathrm{PA}$ ) is used to monitor the reagent gas and helium pressure in the valve system and is used as a reference to ensure reproducible introduction of the gas into the analyzer region. The pressure inside the ion trap is monitored using an ion gauge. In order for the pressure to be monitored as accurately as possible, the plastic electrode spacers provided with the Esquire were replaced by ceramic ones that were drilled with several holes. These holes permit a more even distribution of the introduced gases throughout the vacuum system and allow the ion gauge to be exposed to more of the gas load. Ceramic spacers are used because the plastic spacers provided by Bruker were found to outgas low molecular weight polymers that interfere with the I-M reactions of interest. The pressure provided by the ion gauge is calibrated using the known deprotonation reaction rates of the $13^{+}, 12^{+}$, and $11^{+}$charge states of ubiquitin [57]. A correction factor is then used to obtain the true gas pressure from the ion gauge reading.

\section{Ligand Synthesis}

The ligands used in this study (Figure 1) are generally prepared by reacting diethylenetriamine (DIEN) with aldehyde(s) containing the $\mathrm{R}$ and $\mathrm{R}$ ' groups of interest, according to the well-known reaction that forms Schiff bases. The resulting Schiff bases are then reduced to generate the ligands of interest. All chemicals were obtained from Sigma-Aldrich (St. Louis, MO) and were used without further purification. $\mathrm{H}_{2}(99.99 \%)$ was obtained from Merriam Graves (Springfield, MA). The conditions used in the syntheses can be divided into six general groups.

The first group consists of the following ligands: DIEN-(pyr) $)_{2}$, DIEN-(imi) $)_{2}$ DIEN-(phen) ${ }_{2}$, and DIEN(fur $)_{2}$. The syntheses of each of these ligands have been published previously [54, 58-60]. These ligands are synthesized by mixing the appropriate aldehyde with
DIEN at a 2:1 (aldehyde:DIEN) ratio in anhydrous methanol. This mixture is then reacted for $24 \mathrm{~h}$ in a Parr shaking hydrogenator under a $60 \mathrm{psi}$ atmosphere of $\mathrm{H}_{2}$ over Pd (10\% Pd on carbon). DIEN is reacted with the following aldehydes: 2-pyridinecarboxaldehyde, 4(5)imidazolecarboxaldehyde, benzaldehyde, and 2-furaldehyde, to produce DIEN-(pyr) $)_{2}$ DIEN-(imi) ${ }_{2}$, DIEN(phen $)_{2}$, and DIEN-(fur $)_{2}$ respectively. Because each of these ligands has been synthesized previously, the product is confirmed by simply electrospraying the reaction mixture and observing the relevant $(\mathrm{M}+\mathrm{H})^{+}$ peak (DIEN-(pyr) $)_{2}, \mathrm{~m} / \mathrm{z}$ 286; DIEN-(imi) $)_{2}, \mathrm{~m} / \mathrm{z}$ 264; DIEN-(phen) $)_{2}, m / z$ 284; DIEN-(fur) $)_{2}, m / z$ 264).

The second group of ligands consists of DIEN(thioether $)_{2}$ and DIEN-(thio) $)_{2}$. These ligands are made by reacting 3-(methylthio)propionaldehyde or 2-thiophenecarboxaldehyde with DIEN at a 2:1 ratio for $24 \mathrm{~h}$ in anhydrous methanol. The resulting Schiff base is then reduced using $\mathrm{NaBH}_{4}$. A full reducing equivalent of $\mathrm{NaBH}_{4}$ is added dropwise for $1 \mathrm{~h}$, and the reaction mixture is stirred continuously before being quenched with water after $12 \mathrm{~h}$. The ligands are then extracted using dichloromethane, and the ligands are recovered as yellow oils after allowing the solvent to evaporate. Because anhydrous methanol is critical to the success of this reaction, a molecular sieve (Mallinckrodt Baker Inc., Paris, KY) is used to dry the methanol before these reactions. Both synthetic products are confirmed by electrospraying the reaction mixture and observing the relevant $(\mathrm{M}+\mathrm{H})^{+}$peak (DIEN-(thioether) $)_{2}, \mathrm{~m} / \mathrm{z} 280$; DIEN-(thio) ${ }_{2}, \mathrm{~m} / z$ 296). In addition, ${ }^{1} \mathrm{H}$ NMR was used to verify the successful synthesis of these new ligands, and the following results were obtained: $2.7(\mathrm{~m}, 8 \mathrm{H}$, $\left.\mathrm{CH}_{2}\right), 3.3(\mathrm{~d}, 3 \mathrm{H}, \mathrm{NH}), 3.9\left(\mathrm{~s}, 4 \mathrm{H}, \mathrm{CH}_{2}\right), 6.9(\mathrm{~m}, 4 \mathrm{H}, \mathrm{CH}-$ thio $), 7.3\left(\mathrm{~m}, 2 \mathrm{H}, \mathrm{CH}_{\text {thio }}\right)$ for DIEN-(thio $)_{2}$ and $2.1(\mathrm{~s}, 6 \mathrm{H}$, $\left.\mathrm{CH}_{3}\right), 2.6\left(\mathrm{~m}, 8 \mathrm{H}, \mathrm{CH}_{2}\right), 2.7\left(\mathrm{~m}, 8 \mathrm{H}, \mathrm{CH}_{2}\right), 3.3(\mathrm{~d}, 3 \mathrm{H}$, $\mathrm{NH}), 3.9\left(\mathrm{~m}, 4 \mathrm{H}, \mathrm{CH}_{2}\right)$ for DIEN-(thioether $)_{2}$.

The third group of ligands consists of DIEN(thioether)(imi) and DIEN-(thioether)(pyr). These ligands are synthesized by first mixing 2-pyridinecarboxaldehyde or 4(5)-imidazolecarboxaldehyde with DIEN in anhydrous methanol at a 1:1 ratio. This mixture is then put in a Parr shaking hydrogenator for $24 \mathrm{~h}$ under a $60 \mathrm{psi}$ atmosphere of $\mathrm{H}_{2}$ over $\mathrm{Pd}(10 \% \mathrm{Pd}$ on carbon). The resulting product is then reacted with 3-(methylthio)propionaldehyde at a 1:1 ratio for $24 \mathrm{~h}$. The resulting Schiff base is reduced by a full reducing equivalent of $\mathrm{NaBH}_{4}$ added dropwise for $1 \mathrm{~h}$ and then stirred continuously before being quenched with water after $12 \mathrm{~h}$. The final product is then extracted with dichloromethane, and the product is recovered as a yellow oil after allowing the solvent to evaporate. Both synthetic products are confirmed by electrospraying the reaction mixture and observing the relevant $(\mathrm{M}+\mathrm{H})^{+}$peak (DIEN-(thioether)(imi), $m / z$ 272; DIEN-(thioether)(pyr), $\mathrm{m} / z$ 283). In addition, ${ }^{1} \mathrm{H}$ NMR was used to verify the successful synthesis of these new ligands, and the following results were obtained: $2.1\left(\mathrm{~s}, 3 \mathrm{H}, \mathrm{CH}_{3}\right), 2.6(\mathrm{~m}$, $\left.4 \mathrm{H}, \mathrm{CH}_{2}\right), 2.7\left(\mathrm{~m}, 8 \mathrm{H}, \mathrm{CH}_{2}\right), 3.3(\mathrm{~d}, 3 \mathrm{H}, \mathrm{NH}), 3.8(\mathrm{~m}, 4 \mathrm{H}$, 
$\left.\mathrm{CH}_{2}\right), 7.0\left(\mathrm{~d}, 1 \mathrm{H}, \mathrm{CH}_{\mathrm{imi}}\right), 7.6\left(\mathrm{~s}, 1 \mathrm{H}, \mathrm{CH}_{\text {imi }}\right), 13.0(\mathrm{~s}, 1 \mathrm{H}$,

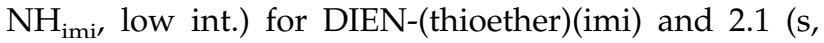
$\left.3 \mathrm{H}, \mathrm{CH}_{3}\right), 2.5\left(\mathrm{~m}, 4 \mathrm{H}, \mathrm{CH}_{2}\right), 2.7\left(\mathrm{~m}, 8 \mathrm{H}, \mathrm{CH}_{2}\right), 3.3(\mathrm{~d}, 3 \mathrm{H}$, $\mathrm{NH}), 3.8\left(\mathrm{~m}, 4 \mathrm{H}, \mathrm{CH}_{2}\right), 7,3\left(\mathrm{~m}, \mathrm{H}, \mathrm{CH}_{\text {pyr }}\right), 7,4(\mathrm{~d}, \mathrm{H}$, $\left.\mathrm{CH}_{\text {pyr }}\right), 7.8\left(\mathrm{~m}, \mathrm{H}, \mathrm{CH}_{\mathrm{pyr}}\right), 8.5\left(\mathrm{~d}, \mathrm{H}, \mathrm{CH}_{\text {pyr }}\right)$ for DIEN(thioether)(pyr).

The fourth group consists of DIEN-(THF) $)_{2}$. This ligand is synthesized by mixing 2-furaldehyde with DIEN at a 2:1 ratio in anhydrous methanol. The mixture is then reacted for $120 \mathrm{~h}$ in a Parr shaking hydrogenator using a 60 psi atmosphere of $\mathrm{H}_{2}$ over $\mathrm{Pd}(10 \% \mathrm{Pd}$ on carbon). The extended reaction time in the Parr hydrogenator is used to enable the complete reduction of both furan rings to tetrahydrofuran (THF). The synthetic product is confirmed by electrospraying the reaction mixture and observing the relevant $(\mathrm{M}+\mathrm{H})^{+}$peak $(\mathrm{m} / \mathrm{z}$ 272). In addition, ${ }^{1} \mathrm{H}$ NMR was used to verify the successful synthesis of this new ligand, and the following results were obtained: $1.1\left(\mathrm{~d}, 8 \mathrm{H}, \mathrm{CH}_{2 \mathrm{THF}}\right), 1.5(\mathrm{~m}$, $\left.4 \mathrm{H}, \mathrm{CH}_{2 \mathrm{THF}}\right), 2.7\left(\mathrm{~s}, 8 \mathrm{H}, \mathrm{CH}_{2}\right), 3.3(\mathrm{~d}, 3 \mathrm{H}, \mathrm{NH}), 3.7(\mathrm{~m}$, $\left.2 \mathrm{H}, \mathrm{CH}_{\mathrm{THF}}\right), 3.8\left(\mathrm{~m}, 4 \mathrm{H}, \mathrm{CH}_{2}\right)$.

The fifth group of ligands consists of DIEN-(THF) (pyr) and DIEN-(THF)(imi). These ligands are synthesized by first mixing 2-furaldehyde with DIEN in anhydrous methanol at a 1:1 ratio. The mixture is then put in a Parr shaking hydrogenator for $120 \mathrm{~h}$ under a 60 psi atmosphere of $\mathrm{H}_{2}$ over $\mathrm{Pd}(10 \% \mathrm{Pd}$ on carbon). The resulting product is then reacted with either 2-pyridinecarboxaldehyde or 4(5)-imidazolecarboxaldehyde at a 1:1 ratio in a Parr shaking hydrogenator for $24 \mathrm{~h}$ under a 60 psi atmosphere of $\mathrm{H}_{2}$ over $\mathrm{Pd}(10 \%$ on carbon) to generate DIEN-(THF)-(pyr) and DIEN-(THF)-(imi), respectively. Both synthetic products are confirmed by electrospraying the reaction mixture and observing the relevant $(\mathrm{M}+\mathrm{H})^{+}$peak $(\mathrm{DIEN}-(\mathrm{THF})(\mathrm{pyr}), m / z 279$; DIEN-(THF)(imi), $m / z$ 268). In addition, ${ }^{1} \mathrm{H}$ NMR was used to verify the successful synthesis of these new ligands, and the following results were obtained: $1.1(\mathrm{~d}$, $\left.4 \mathrm{H}, \mathrm{CH}_{2 \mathrm{THF}}\right), 1.5\left(\mathrm{~m}, 2 \mathrm{H}, \mathrm{CH}_{2 \mathrm{THF}}\right), 2.8\left(\mathrm{~s}, 8 \mathrm{H}, \mathrm{CH}_{2}\right), 3.3$ (d, 3H, NH), 3.7 (m, 1H, $\left.\mathrm{CH}_{\mathrm{THF}}\right), 3.8\left(\mathrm{~m}, 4 \mathrm{H}, \mathrm{CH}_{2}\right), 7,2$ $\left(\mathrm{m}, 1 \mathrm{H}, \mathrm{CH}_{\mathrm{pyr}}\right), 7,4\left(\mathrm{~d}, 1 \mathrm{H}, \mathrm{CH}_{\mathrm{pyr}}\right), 7.8\left(\mathrm{~m}, 1 \mathrm{H}, \mathrm{CH}_{\mathrm{pyr}}\right), 8.5$ $\left(\mathrm{d}, 1 \mathrm{H}, \mathrm{CH}_{\mathrm{pyr}}\right)$ for DIEN-(THF)(pyr) and $1.1(\mathrm{~d}, 4 \mathrm{H}$, $\left.\mathrm{CH}_{2 \mathrm{THF}}\right), 1.5\left(\mathrm{~m}, 2 \mathrm{H}, \mathrm{CH}_{2 \mathrm{THF}}\right), 2.7\left(\mathrm{~s}, 8 \mathrm{H}, \mathrm{CH}_{2}\right), 3.3(\mathrm{~d}$, $3 \mathrm{H}, \mathrm{NH}), 3.6\left(\mathrm{~m}, 1 \mathrm{H}, \mathrm{CH}_{\mathrm{THF}}\right), 3.8\left(\mathrm{~m}, 2 \mathrm{H}, \mathrm{CH}_{2}\right), 4.0(\mathrm{~m}$, $\left.2 \mathrm{H}, \mathrm{CH}_{2}\right), 7.0\left(\mathrm{~d}, 1 \mathrm{H}, \mathrm{CH}_{\mathrm{imi}}\right), 7.6\left(\mathrm{~s}, 1 \mathrm{H}, \mathrm{CH}_{\mathrm{imi}}\right), 13.0$ (s, $1 \mathrm{H}, \mathrm{NH}_{\mathrm{imi}}$, low int.) for DIEN-(THF)(imi).

The sixth group consists of DIEN-(THF)(thioether). This ligand is made by first mixing 2-furaldehyde with DIEN in anhydrous methanol at a 1:1 ratio and then placing it in a Parr shaking hydrogenator for $120 \mathrm{~h}$ under a 60 psi atmosphere of $\mathrm{H}_{2}$ over $\mathrm{Pd}(10 \% \mathrm{Pd}$ on carbon). The resulting product is then mixed with 3-(methylthio)propionaldehyde at a 1:1 ratio and allowed to react for $24 \mathrm{~h}$. After $24 \mathrm{~h}, \mathrm{NaBH}_{4}$ is added dropwise over $1 \mathrm{~h}$ to the resulting solution. The reduction with $\mathrm{NaBH}_{4}$ then proceeds for $12 \mathrm{~h}$ before being quenched by water. The final ligand product is extracted with dichloromethane, and a yellow oil is recovered after allowing the solvent to evaporate. The syn- thetic product is confirmed by electrospraying the reaction mixture and observing the relevant $(\mathrm{M}+\mathrm{H})^{+}$ peak ( $m / z$ 276). In addition, ${ }^{1} \mathrm{H}$ NMR was used to verify the successful synthesis of this new ligand, and the following results were obtained: $1.1\left(\mathrm{~d}, 4 \mathrm{H}, \mathrm{CH}_{2 \text { ringTHF }}\right)$, $1.5\left(\mathrm{~m}, 2 \mathrm{H}, \mathrm{CH}_{2 \mathrm{THF}}\right), 2.1\left(\mathrm{~s}, 3 \mathrm{H}, \mathrm{CH}_{3}\right), 2.6\left(\mathrm{~m}, 4 \mathrm{H}, \mathrm{CH}_{2}\right)$, $2.7\left(\mathrm{~m}, 8 \mathrm{H}, \mathrm{CH}_{2}\right), 3.3(\mathrm{~d}, 3 \mathrm{H}, \mathrm{NH}), 3.7\left(\mathrm{~m}, 1 \mathrm{H}, \mathrm{CH}_{\mathrm{THF}}\right)$, $3.9\left(\mathrm{~m}, 4 \mathrm{H}, \mathrm{CH}_{2}\right)$.

\section{Metal Complex Analysis}

$100 \mu \mathrm{M}$ solutions of the complexes are prepared by mixing equimolar amounts of $\mathrm{CoCl}_{2}$ or $\mathrm{CuCl}_{2}$ solutions and the ligand of interest in methanol or water:methanol (1:1). The solutions are usually allowed to stand for at least a few hours for equilibration. Then, the sample is electrosprayed with a needle voltage of $4-4.5 \mathrm{kV}$ at a flow rate between 1.0 and $2.0 \mu \mathrm{L} / \mathrm{min}$. Typically, a capillary temperature of $150{ }^{\circ} \mathrm{C}$ and a capillary exit offset voltage of $20 \mathrm{~V}$ are used.

The doubly-charged metal complex ions of interest are isolated and allowed to react with acetonitrile for different periods of time. Ion isolation and reaction times are controlled using the Esquire-LC software. The ion trap scan function provided by the Esquire-LC contains several fixed scan delays between ion isolation and acquisition that cannot be changed by the user. Consequently, the shortest reaction time available is around $10.5 \mathrm{~ms}$. The vacuum system temperature was monitored and maintained at $300 \pm 1 \mathrm{~K}$ through all the experiments using a heating blanket. The pressure of acetonitrile in the analyzer region was kept at $3.2 \pm$ $0.3 \times 10^{-7}$ torr and helium was used as a buffer gas with a pressure of $1.0 \pm 0.3 \times 10^{-4}$ torr. Kinetic information is gathered by monitoring the intensities of the parent and product ions for up to $4000 \mathrm{~ms}$ reaction times. Rate constants for the addition of one or more acetonitrile molecules are obtained by fitting the experimental data to the solutions of a series of coupled differential equations. This is accomplished using the KinFit program written by the Dearden group [61].

\section{Results and Discussion}

A typical mass spectrum obtained in these studies is shown in Figure 2. Clearly, one acetonitrile readily adds to Co[DIEN-(pyr) $\left.)_{2}\right]^{2+}$ after $110.5 \mathrm{~ms}$, which was expected given the coordination number (i.e., 5) of this complex, and this single addition of acetonitrile is the only reaction observed. All the ligands studied had 5 heteroatoms [except DIEN-(phen) $)_{2}$ ] and were expected to coordinate the metal in a pentadentate fashion. The reactivity of the complexes of the 12 ligands studied, however, can be divided into two distinct groups. The first group consists of the ligands whose complexes reacted to add two acetonitrile molecules, and the second group consists of ligands that only added one acetonitrile to any significant extent. Thus, the following discussion will be divided into two parts. First, we 


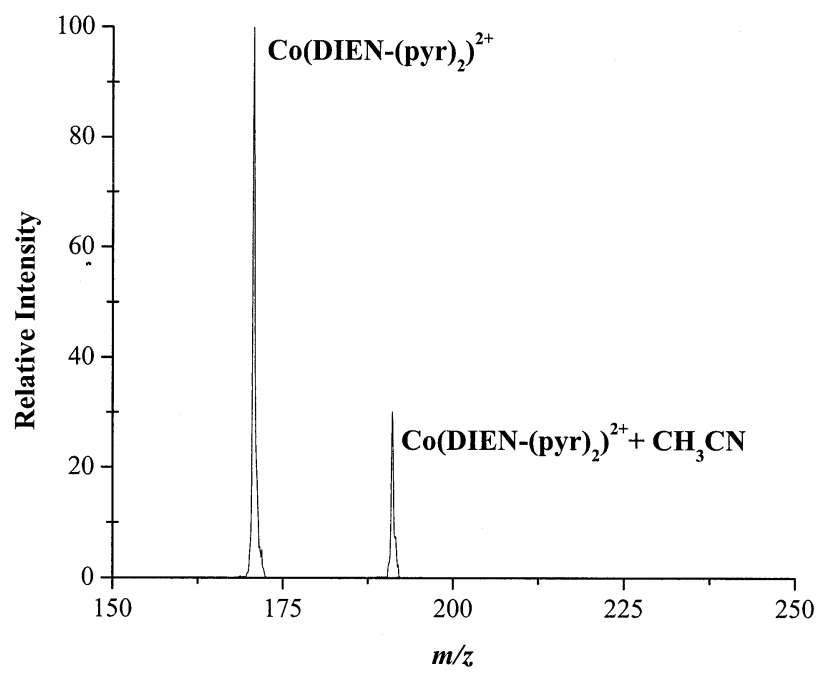

Figure 2. Mass spectrum resulting from a $110.5 \mathrm{~ms}$ reaction of Co[DIEN-(pyr) $]_{2}^{2+}$ with acetonitrile.

will comment on the systems that add two acetonitrile molecules, and then we will discuss complexes that add one acetonitrile.

\section{Metal Complexes that Add Two Acetonitriles}

The complexes of three ligands are found to add predominantly two acetonitrile molecules in the gas phase: DIEN-(fur) $)_{2}$ DIEN-(thio) ${ }_{2}$ and DIEN-(phen) $)_{2}$. Figure 3 shows examples of the kinetic plots that are obtained for the reactions of acetonitrile with Co[DIEN$\left.(\text { fur })_{2}\right]^{2+}$ and $\left.\mathrm{Cu}[\text { DIEN-(fur })_{2}\right]^{2+}$.

The plots in Figure 3 clearly show that the reaction proceeds by an initial addition of one acetonitrile molecule with the rapid disappearance of the parent ion complex. This step is followed by the addition of a second molecule and the establishment of equilibrium. The addition reactions of acetonitrile with the $\mathrm{Co}$ and $\mathrm{Cu}$ complexes of DIEN-(fur) ${ }_{2}$, DIEN-(thio) ${ }_{2}$, and DIEN(phen $)_{2}$ ligands are best described by Eq 1 .

$$
\begin{aligned}
\mathrm{ML}^{2+}+\mathrm{CH}_{3} \mathrm{CN} \stackrel{\mathrm{k}_{1}}{\rightarrow}\left(\mathrm{ML}+\mathrm{CH}_{3} \mathrm{CH}\right)^{2+} \underset{\mathrm{k}_{3}}{\stackrel{\mathrm{k}_{2}}{\rightleftarrows}} \\
\left(\mathrm{ML}+2\left(\mathrm{CH}_{3} \mathrm{CN}\right)\right)^{2+}
\end{aligned}
$$

Fitting the experimental data of the type shown in Figure 3 to the solutions of a series of coupled differential equations derived from Eq 1 allows rate constants for the addition reactions to be obtained (Table 1). The addition of the first acetonitrile molecule to DIEN(fur) $)_{2}$ DIEN-(thio $)_{2}$, and DIEN-(phen) $)_{2}$ complexes is observed to be a very fast process with rate constants in the range of 1.7 to $4.1 \times 10^{-9} \mathrm{~cm}^{3}$ molecule $^{-1} \mathrm{~s}^{-1}$. The reaction is then followed by a sharp decrease in the addition rate of the second acetonitrile which indicates that this reaction is sterically hindered and/or the binding of the second acetonitrile is intrinsically weaker (Table 1). Weaker binding is certainly consistent with
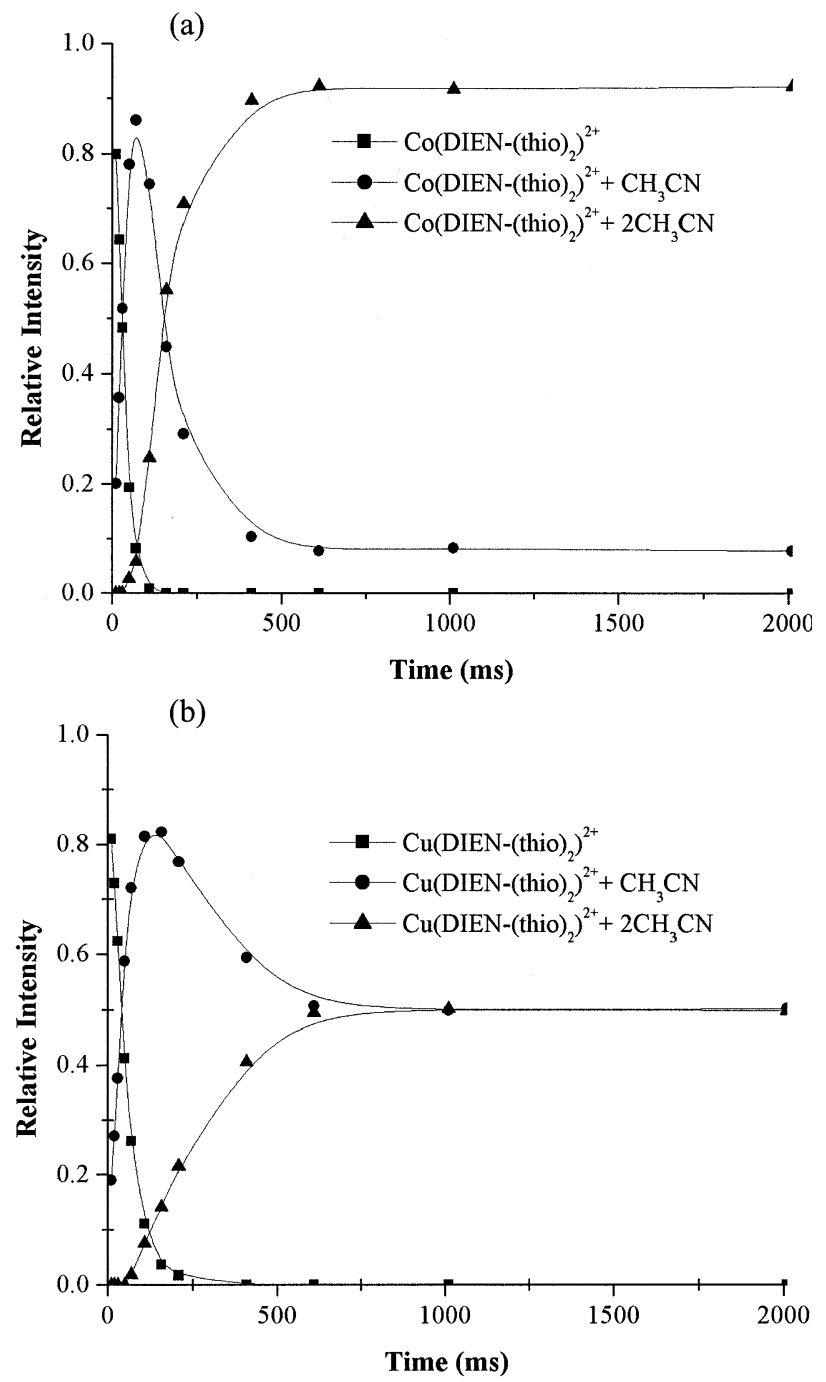

Figure 3. Kinetic plots for the association reactions of (a) Co$\left.[\text { DIEN-(thio) })_{2}\right]^{2+}$ and (b) Cu[DIEN-(thio) $\left.{ }_{2}\right]^{2+}$ complexes with acetonitrile.

previous theoretical and experimental results of gasphase solvation of metal ions [46, 47,62]. The DIENR-R' ligands and the first acetonitrile transfer a significant amount of charge density to the metal. The resulting metal-acetonitrile bond is thus weaker for the second acetonitrile as compared to the first. Also importantly, the presence of the DIEN-R-R' ligand and one acetonitrile ligand causes ligand-ligand repulsion with the second acetonitrile molecule.

Because the ligands examined here have five potential binding sites, we expected the formation of fivecoordinate complexes which, based on previous results $[54,56]$, should add just a single acetonitrile molecule. This expectation, however, clearly is not observed. It seems that DIEN ligands with furan, benzene, and thiophene substituents are not very good ligands for divalent metals. We speculate that one of the furan, benzene, and thiophene groups is either being displaced by acetonitrile or it is not bound at all. Because the DIEN unit is the same in all the complexes used in 
Table 1. Rate constants for the addition of the first $\left(\mathrm{k}_{1}\right)$ and second $\left(\mathrm{k}_{2}\right)$ acetonitrile to the Co(II) and Cu(II) complexes of DIEN(fur) $)_{2}$, DIEN-(phen) $)_{2}$, and DIEN-(thio) . $_{\text {. }}$

\begin{tabular}{|c|c|c|c|c|}
\hline \multirow[b]{3}{*}{ Complex } & \multicolumn{4}{|c|}{ Rate constants $\left(\times 10^{-9} \mathrm{~cm}^{3} \text { molecule }{ }^{-1} \mathrm{~s}^{-1}\right)^{\mathrm{a}}$} \\
\hline & \multicolumn{2}{|c|}{ Co } & \multicolumn{2}{|c|}{$\mathrm{Cu}$} \\
\hline & $\mathrm{k}_{1}$ & $\mathrm{k}_{2}$ & $\mathrm{k}_{1}$ & $\mathrm{k}_{2}$ \\
\hline DIEN-(fur) $)_{2}$ & $4.1 \pm 0.7$ & $0.51 \pm 0.09$ & $2.5 \pm 1.0$ & $0.15 \pm 0.06$ \\
\hline DIEN-(phen $)_{2}$ & $3.1 \pm 0.2$ & $0.86 \pm 0.05$ & $1.9 \pm 0.6$ & $0.4 \pm 0.2$ \\
\hline DIEN-(thio) ${ }_{2}$ & $2.9 \pm 0.5$ & $0.6 \pm 0.1$ & $1.7 \pm 0.3$ & $0.20 \pm 0.06$ \\
\hline
\end{tabular}

aThese values were obtained by fitting eq 1 to the experimental data.

this study, the presence of the aromatic groups likely explains the observed results.

Aromatic heterocycles are known to have different coordination properties than heteroatoms alone. Condensed-phase studies suggest that thiophene has several $\pi$-bonding modes as well as a $\sigma$-bonding mode $\left[\eta^{1}(\mathrm{~S})\right]$. Gas-phase studies of heterocycle coordination to metal ions show that, by itself, thiophene prefers a $\pi$-interaction to form ML or $\mathrm{ML}_{2}$ complexes instead of heteroatom bound $\sigma$-bond interactions [63]. On the other hand in some cases, the $\eta^{1}(\mathrm{~S})$ binding mode to the metal center in solution can be induced by incorporating the thiophene unit into a multidentate ligand [64]. The $\eta^{1}(\mathrm{~S})$ binding mode, however, is generally fairly weak. In fact, it has been established that thiophene units in rigid macrocyclic ligands coordinate poorly or not at all in most transition metal complexes [65-67]. Molecular orbital calculations by Sargent et al. [68] involving sulfur-rich multidentate ligands designed to bind metals in a $\eta^{1}(S)$ fashion, indicate that the magnitude and polarizability of the electronic density of sulfur's lone pairs determine the coordination strength of the ligand. Delocalization of the lone pair charge density through conjugation with adjacent $\pi$-bonds decreases the Lewis basicity of the sulfur and makes thiophene a poor $\sigma$-bonding ligand. All these considerations suggest that if thiophene is $\sigma$-bonded in our complexes then it is not likely to be strongly coordinated to the $\mathrm{Co}$ or $\mathrm{Cu}$, and very likely the thiophene can be displaced by acetonitrile.

Less is known, on the other hand, about the coordination properties of furan. Furan is not as likely to form $\pi$-complexes as thiophene [69], but $\pi$-coordinated and $\eta^{1}(\mathrm{O})$ furan complexes are known $[70,71]$. To assess the prevalence of $\sigma$-bonding versus $\pi$-bonding in the DIEN-(thio) ${ }_{2}$ and DIEN-(fur) $)_{2}$ complexes, a ligand containing two benzene substituents was also studied. Co[DIEN-(phen $\left.)_{2}\right]^{2+}$ and Cu[DIEN-(phen $\left.)_{2}\right]^{2+}$ react in a similar manner to the DIEN-(thio) ${ }_{2}$ and DIEN-(fur $)_{2}$ complexes in that they only add two acetonitrile molecules (data not shown). This result coupled with the similar reaction rate constants in Table 1 indicates that the reactivities of the complexes of all three ligands are fairly similar. This suggests that $\pi$-bonding predominates in the DIEN-(thio) ${ }_{2}$ and DIEN-(fur) $)_{2}$ complexes because $\pi$-bonding is the only mode possible in the DIEN-(phen) ${ }_{2}$ complex. The prevalence of some $\sigma$-bonding in the DIEN-(thio) ${ }_{2}$ and DIEN-(fur $)_{2}$, however, cannot be ruled out with the data at hand.

As was mentioned above, the experimental rate constants for the addition of the first acetonitrile to each system are high. In the case of DIEN-(fur $)_{2}$, DIEN(thio) $)_{2}$, and DIEN-(phen) $)_{2}$ complexes, addition of the first acetonitrile is completed during the first $500 \mathrm{~ms}$ of the reaction, leaving no trace of the parent ion. To gather some insight into the dynamics of this process, we have used the average dipole orientation (ADO) theory to calculate collision rate constants $\left(\mathrm{k}_{\mathrm{ADO}}\right)$ [7275]. We calculate the ADO capture rate constants using the parametrization of ion/polar-molecule collision developed by $\mathrm{Su}$ and Chesnavich [76].

Table 2 lists the reaction efficiencies for the addition of the first acetonitrile. The reaction efficiency is obtained from the ratio of $\mathrm{k}_{1} / \mathrm{k}_{\mathrm{ADO}}$. We find that the efficiencies of these association reactions are very high and occur at rates close to the collision rate. Co complexes are found to be always more reactive than $\mathrm{Cu}$ complexes. In fact, for DIEN-(thio) $)_{2}$, DIEN-(fur $)_{2}$, and

Table 2. Reaction efficiencies for the first acetonitrile addition $\left[\left(k_{1} / k_{\mathrm{ADO}}{ }^{\mathrm{a}}\right) \times 100\right]$ and the second acetonitrile addition $\left(\left(\mathrm{k}_{2} / \mathrm{k}_{\mathrm{ADO}}{ }^{\mathrm{a}}\right) \times\right.$ 100 ) to the $\mathrm{Co}(\mathrm{II})$ and $\mathrm{Cu}(\mathrm{II})$ complexes of DIEN-(fur $)_{2}$, DIEN-(phen $)_{2}$, and DIEN-(thio) ${ }_{2}$

\begin{tabular}{|c|c|c|c|c|}
\hline \multirow[b]{2}{*}{ Complex } & \multicolumn{2}{|c|}{ Reaction Efficiency ${ }^{a, b}$} & \multicolumn{2}{|c|}{ Reaction Efficiency ${ }^{a, c}$} \\
\hline & Co & $\mathrm{Cu}$ & Co & $\mathrm{Cu}$ \\
\hline DIEN-(fur $)_{2}$ & $130 \pm 20$ & $80 \pm 30$ & $17 \pm 3$ & $5 \pm 2$ \\
\hline DIEN-(phen $)_{2}$ & $102 \pm 7$ & $65 \pm 20$ & $29 \pm 2$ & $14 \pm 6$ \\
\hline DIEN-(thio) ${ }_{2}$ & $100 \pm 20$ & $55 \pm 10$ & $19 \pm 5$ & $7 \pm 2$ \\
\hline
\end{tabular}

${ }^{\mathrm{a}}$ The $\mathrm{k}_{\mathrm{ADO}}$ values were calculated using the Average Dipole Orientation theory.

${ }^{\mathrm{b}}$ Reaction efficiency for the addition of the first acetonitrile.

'Reaction efficiency for the addition of the second acetonitrile. 
DIEN-(phen) ${ }_{2}$ complexes of Co the reaction efficiencies are at least $100 \%$. Such behavior has been previously noted for other ion types [77] and is attributed in part to an underestimation of collision rates as calculated by the ADO theory. In ADO theory the ion is considered a point charge, but this certainly does not best depict the metal complexes in this study.

All the association reactions examined in this work are three-body processes which involve formation of a long-lived intermediate complex followed by either collisional stabilization by a third body (He in our case) or spontaneous dissociation of the intermediate back to the reactants $(\mathrm{Eq} 2)$. Separate studies in which the helium pressure was varied were performed to confirm that these reactions do indeed occur via a three-body mechanism. In each case the reaction rate constants increase with an increased helium pressure.

$$
\mathrm{ML}^{2+}+\mathrm{R} \underset{\mathrm{k}_{\mathrm{b}}}{\stackrel{\mathrm{k}_{\mathrm{a}}}{\rightleftarrows}}(\mathrm{ML}+\mathrm{R})^{2+*} \underset{\mathrm{k}_{\mathrm{ac}}[\mathrm{He}]}{\stackrel{\mathrm{k}_{\mathrm{s}}[\mathrm{He}]}{\longrightarrow}}(\mathrm{ML}+\mathrm{R})^{2+}
$$

Using the steady-state approximation the overall association rate constant $\left(\mathrm{k}_{1}\right)$ for the experimentally observed addition of $\mathrm{R}$ (acetonitrile in our case) can be determined ( $\mathrm{Eq} 3)$ :

$$
\mathrm{k}_{1}=\frac{\mathrm{k}_{\mathrm{a}}[\mathrm{R}] \mathrm{k}_{\mathrm{s}}[\mathrm{He}]}{\mathrm{k}_{\mathrm{b}}+\mathrm{k}_{\mathrm{s}}[\mathrm{He}]}
$$

Our experimental results show that the addition of the first acetonitrile does not seem to occur with the subsequent dissociation back to the reactants but rather continues with the rapid addition of a second acetonitrile. Furthermore, an equilibrium is established between the complex with one acetonitrile added and the complex with two acetonitriles added. The addition of the first acetonitrile $\left(\mathrm{k}_{1}\right)$ then likely occurs under conditions in which either the rate of collisional stabilization $\left(\mathrm{k}_{\mathrm{s}}[\mathrm{He}]\right)$ of the excited intermediate is very high or the dissociation rate constant $\left(\mathrm{k}_{\mathrm{b}}\right)$ of the excited intermediate is very low. In either case Eq 3 simplifies to Eq 4.

$$
\mathrm{k}_{1}=\mathrm{k}_{\mathrm{a}}[\mathrm{R}]
$$

The reaction efficiencies in Table 2 reveal that the association of the first acetonitrile occurs at about the calculated collision rate for each of the DIEN-(fur) $)_{2}$, DIEN-(phen) $)_{2}$, and DIEN-(thio) ${ }_{2}$ complexes, confirming our speculation about the relative magnitudes of $\mathrm{k}_{\mathrm{s}}$ and $\mathrm{k}_{\mathrm{b}}$. This result says that the probability that a collision between the complexes and the first acetonitrile will lead to a long-lived excited intermediate is close to one for each of the complexes. Under conditions in which the acetonitrile adds so rapidly, the association rate constant for the addition of the first acetonitrile $\left(\mathrm{k}_{1}\right)$ should not contain much chemical information, at least for the Co(II) complexes, but should be simply a reflec-
Table 3. Constants for the equilibrium between the addition of one and two acetonitrile molecules for the $\mathrm{Co}(\mathrm{II})$ and $\mathrm{Cu}(\mathrm{II})$ complexes of DIEN-(fur) $)_{2}$, DIEN-(phen) $)_{2}$, and DIEN-(thio) ${ }_{2}$

\begin{tabular}{lcc}
\hline & \multicolumn{2}{c}{ Equilibrium constants $^{\mathrm{a}}$} \\
\cline { 2 - 3 } Complex & Co & $\mathrm{Cu}$ \\
\hline \hline DIEN-(fur) ${ }_{2}$ & $90 \pm 30$ & $1.2 \pm 0.4$ \\
DIEN-(phen) $_{2}$ & $>300^{\mathrm{b}}$ & $7 \pm 3$ \\
DIEN-(thio) $_{2}$ & $21 \pm 5$ & $1.2 \pm 0.1$ \\
\hline
\end{tabular}

${ }^{a}$ The equilibrium constant is obtained from the following eq: $\mathrm{K}=\mathrm{k}_{2} / \mathrm{k}_{3}$; where $k_{2}$ and $k_{3}$ are found by plotting the experimental data to eq 1 . ${ }^{b}$ The fitting for the Co(DIEN-(phen $\left.)_{2}\right)^{2+}$ complex failed to provide a non-negative value for $k_{3}$, so the equilibrium constant was estimated from mass spectra taken under conditions in which the equilibrium was established.

tion of the collision rate constant, which is mainly governed by the electrostatic attraction of an ion to a neutral with a dipole.

The addition of the second acetonitrile has a much lower rate constant, and thus the dynamics of its addition may provide some chemical information because $k_{b}$ will influence the observed reaction rate. The reaction rate constants $\left(k_{2}\right)$ for the addition of the second acetonitrile should be indicative of any electronic "tuning" of the metal. Eqs 2 and 3 are identical for the addition of the second acetonitrile, and the inverse dependence of $\mathrm{k}_{2}$ on $\mathrm{k}_{\mathrm{b}}$ means that the binding strength of the acetonitrile should be reflected in $\mathrm{k}_{2}$. The rate constant for the dissociation $\left(\mathrm{k}_{\mathrm{b}}\right)$ of the excited intermediate can be described by RRKM theory, and a key parameter in the RRKM description is the strength of the interaction between the second acetonitrile and the complex. Thus, the rate constant, $k_{2}$, should be related to the binding strength of acetonitrile and is indicative of metal "tuning". Because $\mathrm{k}_{2}$ also reflects the magnitude of $\mathrm{k}_{\mathrm{a}}$, which is related to the collision rate constant, a more accurate depiction of $k_{b}$ can be obtained by calculating the reaction efficiencies for the addition of the second acetonitrile (Table 2). The reaction efficiencies take into account the differences in collision rate constants for each complex with acetonitrile, and thus more closely reflect the differences in $\mathrm{k}_{2}$ that are caused by differences in $\mathrm{k}_{\mathrm{b}}$. The equilibrium constant is also a good indicator of any chemical information because it directly relates to $\Delta \mathrm{G}$ of the reaction, and these values are listed in Table $3 . \Delta \mathrm{H}$, which is related to $\Delta \mathrm{G}$ assuming $\Delta \mathrm{S}$ is similar for all the reactions, is essentially the binding strength of the added ligand and should be affected as the ligands "tune" the electronic density around the metal.

The trend in reaction efficiencies (Table 2) and equilibrium constants (Table 3 ) is the following for Co: DIEN-(phen $)_{2}>$ DIEN-(fur) $)_{2}>$ DIEN-(thio) $)_{2}$. For $\mathrm{Cu}$ the trend is slightly different: DIEN-(phen $)_{2}>$ DIEN(fur $)_{2} \approx$ DIEN-(thio) $)_{2}$. These trends can be explained by considering the strength of the $\pi$-interaction for each substituent. When included in a multidentate ligand such as DIEN-(phen) $)_{2}$, the phenyl substituent is not 
completely free to arrange itself around the metal. The presence of a relatively strongly-binding amine group that is one carbon removed from the phenyl ring limits the ability of the phenyl to orient itself optimally around the metal for an $\eta^{6}$-binding geometry. So, even though previous experimental results show that benzene binds more strongly to transition metals such as $\mathrm{Co}^{+}$and $\mathrm{Fe}^{+}$than thiophene or furan $[63,69,78,79]$, its inability to obtain an optimum orientation in our complexes causes it to ultimately bind less strongly to $\mathrm{Co}(\mathrm{II})$ and $\mathrm{Cu}(\mathrm{II})$, probably binding in an $\eta^{2}$ fashion. The net result is that less electron density is donated to the metal by the phenyl group than by the thiophene or furan functional groups, and the reactivities of the DIEN-(phen) $)_{2}$ complexes are consequently greater. Unlike the phenyl substituent where the $\pi$ density is delocalized over the entire ring, in furan and thiophene the $\pi$ density is more localized around the heteroatoms and two of the carbons in the ring. In the furan ring the $\pi$ density is localized around the oxygen and carbons 2 and 3 (C2 and C3), and in thiophene the $\pi$ density is localized around sulfur and carbons 1 and 4 (C1 and C4). In each case the increased localization of the electronic density occurs at sites that are more easily oriented around the metal. The similar reactivity of the DIEN-(fur) $)_{2}$ and DIEN-(thio) ${ }_{2}$ complexes further argues for $\pi$ interactions with the metal since the greater dipole moment of furan $(0.66 \mathrm{D}$ versus $0.55 \mathrm{D})$ would allow furan to have stronger $\sigma$ interactions than thiophene, resulting in stronger binding to the metal and thus lower reactivity. We are unable to explain the relatively low equilibrium constant for the $\mathrm{Co}$ (DIEN)-(thio) ${ }_{2}^{2+}$ complex relative to $\mathrm{Co}$ (DIEN)-(fur $)_{2}^{2+}$, especially since the reaction efficiencies for these complexes are similar. Given the relative dipole moments of the furan and thiophene groups, however, this result further suggests that the thiophene and furan groups bind to the metal via $\pi$ interactions.

\section{Metal Complexes that Add One Acetonitrile}

Nine ligands are found to add predominantly one acetonitrile molecule when complexed to Co(II) and $\mathrm{Cu}$ (II): DIEN-(pyr) $)_{2}$, DIEN-(imi) $)_{2}$, DIEN-(THF) ${ }_{2}$, DIEN(thioether) ${ }_{2}$, DIEN-(THF)(thioether), DIEN-(imi)(THF), DIEN-(pyr)(THF), DIEN-(imi)(thioether), and DIEN(pyr)(thioether). Figure 4 displays typical kinetic plots for the reactions of Co[DIEN-(imi) $\left.)_{2}\right]^{2+}$ and Cu[DIEN$\left.(\mathrm{imi})_{2}\right]^{2+}$ with acetonitrile. The kinetic plots reveal that the reaction proceeds predominantly by the addition of one acetonitrile molecule, and an equilibrium is established after about $1000 \mathrm{~ms}$. Even though the addition of a second acetonitrile is very small or in some cases does not occur in the reactions of these complexes, the kinetics data are fit by considering Eq 5 .

$$
\mathrm{ML}^{2+}+\mathrm{CH}_{3} \mathrm{CN} \underset{\mathrm{k}_{2}}{\stackrel{\mathrm{k}_{1}}{\rightleftarrows}}\left(\mathrm{ML}+\mathrm{CH}_{3} \mathrm{CN}\right)^{2+} \underset{\mathrm{k}_{4}}{\stackrel{\mathrm{k}_{3}}{\rightleftarrows}}
$$
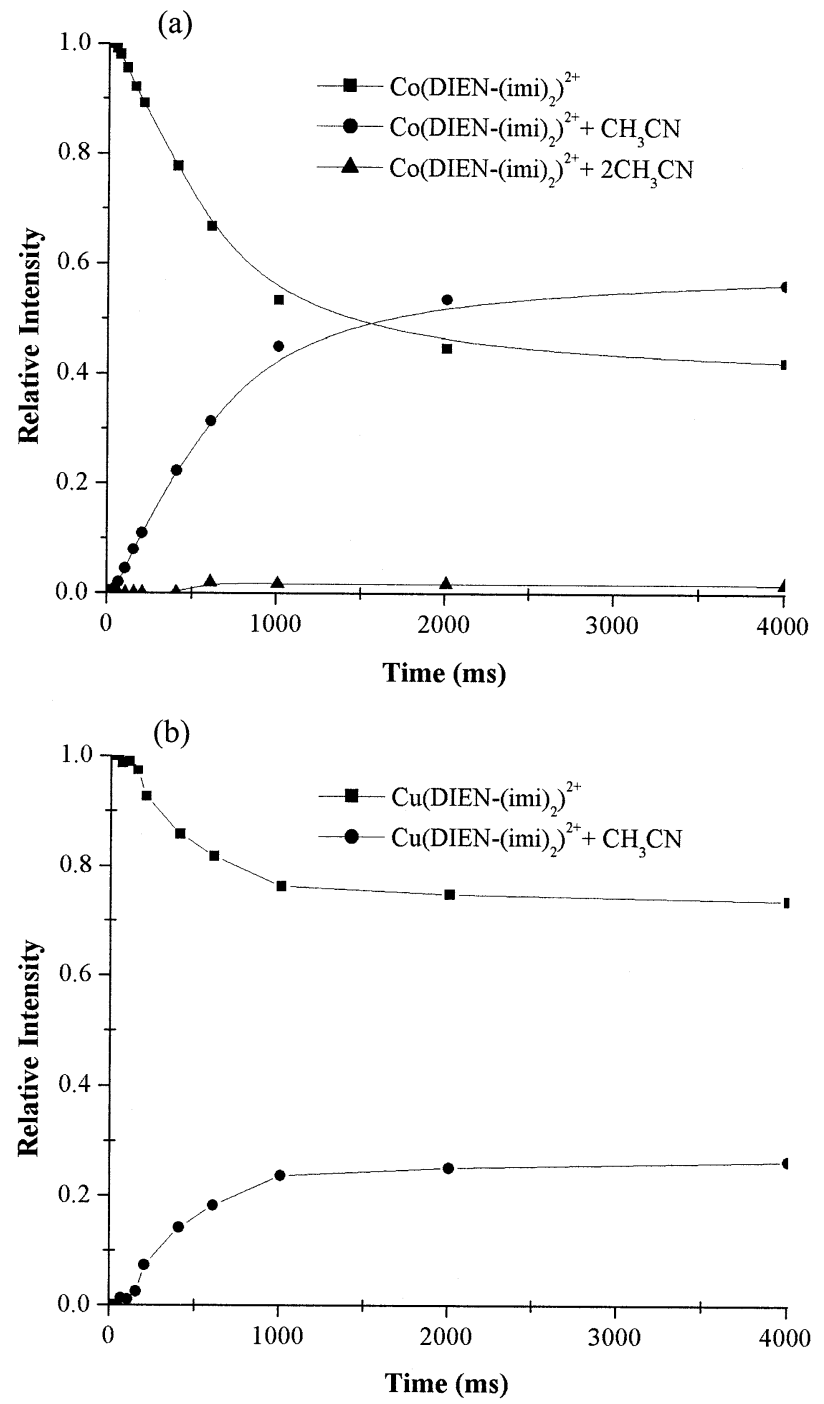

Figure 4. Kinetic plots for the association reactions of (a) Co$\left.[\text { DIEN-(imi) })_{2}\right]^{2+}$ and (b) $\mathrm{Cu}\left[\mathrm{DIEN}-(\mathrm{imi})_{2}\right]^{2+}$ with acetonitrile.

$$
\left(\mathrm{ML}+2\left(\mathrm{CH}_{3} \mathrm{CH}\right)\right)^{2+}
$$

In general, results indicate that $\mathrm{Co}(\mathrm{II})$ complexes are more reactive than $\mathrm{Cu}(\mathrm{II})$ complexes. The ligands, DIEN-(pyr) $)_{2}$ DIEN-(imi) $)_{2}$ DIEN-(THF) $)_{2}$, DIEN-(thioether) ${ }_{2}$, DIEN-(THF)(thioether), DIEN-(imi)(THF), DIEN-(pyr)(THF), DIEN-(imi)(thioether), and DIEN(pyr)(thioether), all possess five possible binding sites and their complexes react, as expected, by adding only one acetonitrile molecule to any significant extent. A quick examination of the functional groups involved in coordination reveals that all are good $\sigma$-bonding ligands. The possibility of a $\pi$-interaction with the aromatic residues in this group of ligands is unlikely based on the known complexing modes of imidazole and pyridine with divalent metals. For some complexes, a small addition of a second acetonitrile molecule is observed. Because these complexes are 5-coordinate, the second acetonitrile either displaces one of the coor- 
Table 4. Rate constants and reaction efficiencies $\left[\left(\mathrm{k}_{1} / \mathrm{k}_{\mathrm{ADO}}{ }^{\mathrm{a}}\right) \times 100\right]$ for the addition of one acetonitrile to selected complexes of $\mathrm{CO}(\mathrm{II})$ and $\mathrm{Cu}(\mathrm{II})$

\begin{tabular}{|c|c|c|c|c|}
\hline \multirow[b]{2}{*}{ Complex } & \multicolumn{2}{|c|}{$\begin{array}{c}\text { Rate constants }\left(\times 10^{-10} \mathrm{~cm}^{3}\right. \\
\left.\text { molecule }{ }^{-1} \mathrm{~s}^{-1}\right)^{\mathrm{a}}\end{array}$} & \multicolumn{2}{|c|}{ Reaction Efficiency ${ }^{b}$} \\
\hline & Co & $\mathrm{Cu}$ & Co & $\mathrm{Cu}$ \\
\hline DIEN-(THF) $)_{2}$ & $6 \pm 1$ & $2.6 \pm 0.7$ & $20 \pm 4$ & $9 \pm 2$ \\
\hline DIEN-(THF)(thioether) & $4.1 \pm 0.6$ & $2.5 \pm 0.5$ & $13 \pm 2$ & $8 \pm 2$ \\
\hline DIEN-(thioether) ${ }_{2}$ & $3.5 \pm 0.4$ & $2.8 \pm 0.1$ & $11 \pm 1$ & $9.3 \pm 0.4$ \\
\hline DIEN-(THF)(pyr) & $3 \pm 1$ & $1.9 \pm 0.2$ & $11 \pm 4$ & $6.3 \pm 0.8$ \\
\hline DIEN-(THF)(imi) & $2.8 \pm 0.1$ & $1.7 \pm 0.4$ & $9.2 \pm 0.3$ & $5.7 \pm 0.1$ \\
\hline DIEN-(pyr $)_{2}$ & $2.3 \pm 0.4$ & $0.9 \pm 0.2$ & $7 \pm 1$ & $3.1 \pm 0.6$ \\
\hline DIEN-(thioether)(pyr) & $1.7 \pm 0.2$ & $1.1 \pm 0.2$ & $5.7 \pm 0.6$ & $3.8 \pm 0.2$ \\
\hline DIEN-(imi) $)_{2}$ & $1.0 \pm 0.3$ & $0.7 \pm 0.3$ & $3.2 \pm 0.9$ & $2.3 \pm 0.9$ \\
\hline DIEN-(thioether)(imi) & $0.8 \pm 0.2$ & $0.9 \pm 0.2$ & $2.6 \pm 0.8$ & $2.9 \pm 0.5$ \\
\hline
\end{tabular}

aThese values were obtained by fitting eq 5 to the experimental data.

${ }^{b}$ The $\mathrm{k}_{\mathrm{ADO}}$ values were calculated using the Average Dipole Orientation theory.

dinating groups or adds as an outer-sphere ligand by $\mathrm{H}$-bonding with the ligand. At this point our data does not allow us to unambiguously distinguish between the two possibilities, but in either case the addition of the second acetonitrile is fairly insignificant and never exceeds $10 \%$ relative intensity for any of the complexes even after $4000 \mathrm{~ms}$ reaction times. In fact, for all cases the addition of the second acetonitrile is insignificant $(<5 \%)$ at reaction times below $500 \mathrm{~ms}$. In a previous study by Vachet et. al. [54], the addition of a reagent ligand that exceeded $20 \%$ relative intensity after $100 \mathrm{~ms}$ was arbitrarily defined as a successful reaction. Thus, in those previous experiments, for example, 5-coordinate complexes were found to only add one pyridine molecule under the arbitrarily defined conditions. If this same threshold is extended to $150 \mathrm{~ms}$, then acetonitrile, like pyridine, can act as a titration reagent to identify 5 -coordinate complexes in the present context. Furthermore, the present results show that this idea of coordination number determination can be extended to complexes with ligands having coordinating heteroatoms other than nitrogen if the binding groups are good $\sigma$-donors.

Table 4 lists the rate constants for the addition of one acetonitrile molecule to the $\mathrm{Co}(\mathrm{II})$ and $\mathrm{Cu}$ (II) complexes. In almost all cases for a given ligand, the rate constants for $\mathrm{Co}(\mathrm{II})$ complexes are higher than for $\mathrm{Cu}$ (II) complexes. The reasons for the differences in reactivity for each metal will not be discussed here but rather will be the subject of a future paper. Using ADO theory to calculate the collision rate constants of these ion-molecule processes, Table 4 also reports the reaction efficiency values $\left(\mathrm{k}_{1} / \mathrm{k}_{\mathrm{ADO}}\right)$ for the various complexes that add one acetonitrile. A comparison of the reaction efficiencies in Table 4 with the ones in Table 2 clearly show that the addition of the first acetonitrile to these complexes is much less efficient and occurs at rates well below the collision rate. In fact, the highest reaction efficiency observed is only $20 \pm 4 \%$ [Co(DIEN$\left.\left.\{\mathrm{THF}\}_{2}\right)^{2+}\right]$. Reaction rates below the collision rate suggest that the dynamics of these reactions may contain some chemical information. The equilibrium constants (Table 5) for these reactions also contain some chemical information because they are indicative of the binding strength of acetonitrile and say something about the different degrees to which each ligand tunes $\mathrm{Co}$ and $\mathrm{Cu}$. Of note in Table 5 is that, in general, the complexes with the highest equilibrium constants also had the highest standard deviations. The complexes with the highest equilibrium constants are also likely the ones with the most negative $\Delta \mathrm{H}$ values and thus are going to be the most sensitive to slight temperature variations.

Considering that the DIEN unit is the same in all complexes, the presence of different functionalities in the ligands is responsible for the observed results. Close examination of the values in Tables 4 and 5 show that the reaction depends on the types of heteroatoms in the coordination sphere of the complex. The trends observed in the reaction efficiencies and equilibrium constants are identical for a given metal with a couple exceptions. The trends for the complexes of $\mathrm{Cu}$ (II) show decreasing reaction efficiencies and equilibrium constants in the following order:

DIEN-(thioether) $)_{2}>$ DIEN-(THF)(thioether) $>>$

Table 5. Equilibrium constants for the addition of acetonitrile to selected $\mathrm{Co}(\mathrm{II})$ and $\mathrm{Cu}(\mathrm{II})$ complexes

\begin{tabular}{lcc}
\hline & \multicolumn{2}{c}{ Equilibrium constants $^{\mathrm{a}}$} \\
\cline { 2 - 3 } Ligand & Co & $\mathrm{Cu}$ \\
\hline \hline DIEN-(THF) & $220 \pm 60$ & $5 \pm 1$ \\
DIEN-(THF)(thioether) & $130 \pm 25$ & $6 \pm 1$ \\
DIEN-(THF)(pyr) & $75 \pm 30$ & $2.3 \pm 0.5$ \\
DIEN-(THF)(imi) & $65 \pm 20$ & $2.7 \pm 0.2$ \\
DIEN-(thioether) & $10 \pm 2$ & $7 \pm 2$ \\
DIEN-(thioether)(pyr) & $4.7 \pm 0.3$ & $1.1 \pm 0.4$ \\
DIEN-(pyr) & $3 \pm 1$ & $0.9 \pm 0.2$ \\
DIEN-(imi) & $1.4 \pm 0.2$ & $0.5 \pm 0.1$ \\
DIEN-(thioether)(imi) & $1.2 \pm 0.1$ & $1.1 \pm 0.1$ \\
\hline
\end{tabular}

${ }^{a}$ The equilibrium constants were determined from the following eq: $\mathrm{K}=$ $k_{1} / k_{2} ;$ where $k_{1}$ and $k_{2}$ are found by fitting the experimental data to eq 5 . 
DIEN-(THF) $)_{2}>$ DIEN-(THF)(pyr) $>$ DIEN-(THF)(imi) $>$ DIEN-(thioether)(pyr) $\approx$ DIEN-(thioether)(imi) $>$ DIEN-(pyr) $)_{2}>$ DIEN-(imi) . $_{\text {. }}$

There are only two differences between the trends for reaction efficiencies and equilibrium constants for the $\mathrm{Cu}$ (II) complexes. The first difference is the interchange in the trend for the DIEN-(THF)(imi) and DIEN(THF)(pyr) complexes. The reaction efficiency for the DIEN-(THF)(pyr) complex is slightly higher than in the DIEN-(THF)(imi) complex, but the equilibrium constant for the reaction of this complex is slightly lower than DIEN-(THF)(imi). The differences, however, are fairly small and are within the experimental error, and thus they are seemingly insignificant. The second difference is the interchange in trend for the DIEN-(THF) $)$ (thioether) and DIEN-(THF) ${ }_{2}$ complexes. The reaction efficiency for the DIEN-(THF) ${ }_{2}$ complex is slightly higher than the value for the DIEN-(THF)(thioether) complex, whereas the DIEN-(THF)(thioether) complex has a slightly higher equilibrium constant. Again, these differences are very small and are in fact within the experimental error of the measurement. For the $\mathrm{Co}(\mathrm{II})$ complexes the trend is essentially the following:

DIEN-(THF) $)_{2}>$ DIEN-(THF)(thioether) $>$ DIEN(thioether) $)_{2}>$ DIEN-(THF)(pyr) $>$ DIEN-(THF)(imi) $>$ DIEN-(thioether) $(\text { pyr) }>\text { DIEN-(pyr) })_{2}>$ DIEN-(imi) $)_{2}>$ DIEN-(thioether)(imi).

One minor difference in trends of reaction efficiencies and equilibrium constants for Co(II) complexes is the flipping in positions of the DIEN-(pyr $)_{2}$ and DIEN(pyr)(thioether) complexes, but the large relative standard deviation associated with the DIEN-(pyr) ${ }_{2}$ complex suggests that these complexes may actually have similar reactivity. The most significant difference in the trends for reaction efficiencies and equilibrium constants for the $\mathrm{Co}(\mathrm{II})$ complexes is the relatively low equilibrium constant (or relatively high reaction efficiency, depending on the perspective) of the DIEN(thioether) $)_{2}$ complex. To offer an explanation for this difference, a brief description as to what these values represent seems warranted.

The equilibrium constant is directly related to $\Delta \mathrm{G}$ of the reaction, and thus it is a thermochemical parameter that relates the binding strength $(\Delta \mathrm{H})$ of acetonitrile to the complex. The reaction efficiency, which is a normalized value of $k_{1}$ that corrects for the slight differences in the collision rate constants for each complex, reflects both kinetic and thermochemical information. The reaction efficiency [or association rate constant $\left(k_{1}\right)$, as seen in Eq. 3] is affected by both the formation $\left(k_{a}\right)$ and dissociation $\left(\mathrm{k}_{\mathrm{b}}\right)$ kinetics of the excited intermediate. The formation rate constant $\left(\mathrm{k}_{\mathrm{a}}\right)$ will likely be affected by sterics, while $k_{b}$ will be determined by the bond strength of acetonitrile to the metal complex as well as the number and energy spacing of the vibrational modes in the long-lived intermediate. Consequently, there should be a correlation between the equilibrium constants and reaction efficiencies because both reflect the binding strength of acetonitrile, but the reaction efficiencies should contain additional information about sterics.

Considering the slight differences between the meaning of the two values, an explanation can be offered for the anomaly in the trends of the reaction efficiencies and equilibrium constants caused by the Co[DIEN-(thioether) $\left.)_{2}\right]^{2+}$. If we use the equilibrium constant as our frame of reference, the relatively high reaction efficiency can be explained by considering two factors. First, because of the large size of $\mathrm{S}$ relative to $\mathrm{O}$ or $\mathrm{N}$, the $\mathrm{Co}-\mathrm{S}$ bonds are going to be longer than the analogous $\mathrm{Co}-\mathrm{O}$ and $\mathrm{Co}-\mathrm{N}$ bonds, and thus the functionality adjacent to the sulfur (i.e., $\mathrm{CH}_{2}$ groups) will be further from the metal as well. This fact might allow the acetonitrile to approach Co with less steric interference, thus increasing its reaction efficiency by increasing $k_{a}$. Second, Co[DIEN-(THF)(pyr) $]^{2+}$ and Co[DIEN(THF)(imi) $]^{2+}$ may have reaction efficiencies that are actually lower than expected due to the steric interference of the pyridine and imidazole rings. In these complexes the rings may hinder the approach of acetonitrile to a greater extent than the thioether functionality causing them to have lower reaction rates despite ultimately binding more strongly to acetonitrile (i.e. have higher equilibrium constants).

A possible weakness in this argument is that the same behavior would be expected of the Cu[DIEN(thioether) $\left.)_{2}\right]^{2+}$ complex, but it is not observed. A possible explanation for the absence of this effect in the $\mathrm{Cu}$ (II) complexes involves the probable coordination number of the $\mathrm{Cu}(\mathrm{II})$ complexes as compared to the $\mathrm{Co}$ (II) complexes. Previous gas-phase studies show that 5-coordinate $\mathrm{Cu}$ (II) complexes are generally unreactive because of the well known Jahn-Teller effects that make the addition of a sixth donor group difficult $[54,56]$. Because the $\mathrm{Cu}$ (II) complexes in the current study do react with acetonitrile, they are likely 4-coordinate. Recent solution studies seem to provide additional confirmation of this possibility as Cu[DIEN-(pyr $)_{2}$ ] was found to exist to a significant degree as a 4-coordinate species in solution [80]. The binding of the ligands to $\mathrm{Cu}$ (II) then provides less steric interference in general for all the $\mathrm{Cu}$ (II) complexes, thus making acetonitrile addition less susceptible to steric constraints than in the 5-coordinate $\mathrm{Co}$ (II) complexes.

In general the trends in Tables 4 and 5 show that the more nitrogens the complexes have in their coordination spheres the lower the equilibrium constants are. Within the group of nitrogen-containing ligands, complexes with imidazole groups are less reactive than ligands with pyridine groups. This result likely is due to the better $\sigma$-bonding of imidazole as reflected by its higher dipole moment relative to pyridine (3.8 D versus $2.215 \mathrm{D})$. Furthermore, we notice that the more oxygen or sulfur functional groups present the more reactive the complexes, with oxygen-containing complexes being slightly more reactive than sulfur-containing complexes. This trend presumably reflects the greater extent of orbital overlap that nitrogen functional groups gen- 
erally have with first-row divalent transition metals when compared to oxygen or sulfur donors. The effects of the donor groups on the equilibrium constants also seem to be somewhat additive. For example, the equilibrium constants for the DIEN-(THF)(imi) complexes fall in between the values for the DIEN-(THF) $)_{2}$ and DIEN-(imi) ${ }_{2}$ complexes. Similarly, the DIEN-(THF)(pyr) complexes have equilibrium constants between the values of DIEN-(THF) $)_{2}$ and DIEN-(pyr) $)_{2}$ complexes. This additive effect is entirely consistent with solution data that shows both stability constants and ligand field stabilization energies generally are subject to similar additive/subtractive effects as the type of donating groups are changed [81]. The most significant exception to these trends are for complexes that contain one thioether group and four nitrogen binding groups. The equilibrium constants for these complexes seem to be lower than would be expected based upon the idea of additive effects of the donor groups. The most extreme case involves the Co[DIEN-(thioether)(imi) ${ }^{2+}$ complex which has the lowest equilibrium constant of all the Co(II) complexes.

The relatively low equilibrium constants for complexes with one thioether group and one imidazole or pyridine group are indicative of greater overlap of the ligand with the metal such that the acetonitrile binding strength is reduced. A possible explanation for the behavior of the complexes with a single thioether group can be offered by considering the hard and soft acid and base (HSAB) principle that has been put forth by Pearson [82]. This principle states that hard acids (metals) prefer interactions with hard bases (donor atoms) and soft acids prefer interactions with soft bases. The hard and soft descriptors are related to the polarizability of the metal or donor group and describe the predominant nature of the interaction. Hard acids and hard bases are not very polarizable and are more likely to interact electrostatically than soft acids and soft bases, which are more polarizable and have more covalent nature to their interactions. According to this principle first-row divalent transition metals such as $\mathrm{Co}(\mathrm{II})$ and $\mathrm{Cu}(\mathrm{II})$ are borderline acids and thus prefer borderline bases, of which pyridine and imidazole are good examples. THF is classified as a hard base, and thioethers are classified generally as soft bases. As a result borderline acids such as $\mathrm{Co}$ (II) and $\mathrm{Cu}$ (II) have stronger interactions with nitrogen-containing bases such as imidazole and pyridine than either with hard (e.g., THF) or soft (e.g., thioether) bases.

Our data is consistent with the HSAB picture since the ligands with imidazole and pyridine functional groups are generally less reactive than the sulfur- and oxygen-containing analogs. The apparent exceptions are when one thioether functional group is mixed with a pyridine and/or imidazole groups. A possible explanation for this exception can be given by considering the nature of the electron density around the metal when bound to a pentadentate ligand containing an imidazole or pyridine. Because pyridine and imidazole provide good overlap for the metal, they are able to considerably decrease the electron deficiency of the metal. In doing so the polarizability of the metal center is increased because of the now greater electron density around it. The metal effectively is made softer in an HSAB sense, allowing interactions with the single thioether to be stronger. In contrast, the softening of the metal does not increase the preference for THF, which is a hard base. Consequently, the complexes with a single THF group and imidazole and/or pyridine groups are still fairly reactive but less reactive than DIEN-(THF) ${ }_{2}$ complexes because of the presence of at least one good nitrogen donor. The relatively high reactivity of the DIEN-(thioether) ${ }_{2}$ complexes can be explained by considering that the amine groups along the main chain of the ligand are not as effective as pyridine or imidazole in increasing the polarizability or "softness" of the metals. Amine groups are generally considered to be poorer donor groups than pyridine or imidazole for first-row divalent transition metals. Similarly, the hard THF group in the DIEN-(THF)(thioether) complexes is unable to soften the metals, and thus the reactivity of these complexes is as expected based on additive effects.

The idea of a metal center behaving harder or softer depending on the ligands around it is a concept that is known to occur in solution and has been particularly noted to occur as a result of steric interactions [81]. In addition, it is well known that the hardness of the metal center in $\mathrm{M}(\mathrm{N}-\mathrm{N})^{2+}$ complexes, where $(\mathrm{N}-\mathrm{N})$ is a diimine ligand such as 2,2'-bipyridine or 1,10-phenanthroline and $\mathrm{M}$ is a first-row transition metal, changes relative to the aqueous metal complex [83-85]. The increased hardness of the metal center in these diimine complexes has been explained by considering the removal of electron density from the metal by the large $\pi$-acceptor capacity of the diimine ligands. In our experiments, we observe the exact opposite trend such that the metal is made softer by the strong electron donating capacity of the good $\sigma$-donors, imidazole and pyridine. Imidazole and pyridine, of course, have a small degree of $\pi$-acceptor capacity, but in our case this capacity does not seem to be great enough to accept electron density back from the metal. Systematic studies are currently underway to further understand and confirm the apparent tuning of metal softness as particular ligands are placed in the coordination sphere.

Another point of interest is the greater relative reactivity (i.e., higher equilibrium constant) of $\mathrm{Cu}$ $\left[D I E N-(\text { thioether })_{2}\right]^{2+}$ when compared to Co[DIEN(thioether $\left.)_{2}\right]^{2+}$. The slightly larger ionic radius of $\mathrm{Co}(\mathrm{II})$ in pentadentate complexes may make it more easily polarized than $\mathrm{Cu}$, thus allowing stronger interactions with the thioether groups. This effect would even be more pronounced if the $\mathrm{Cu}$ (II) complex is considered to be a 4-coordinate species, as is suspected based on considerations mentioned above. The ionic radii of 4-coordinate $\mathrm{Cu}(\mathrm{II})$ complexes are usually found to be around $0.57 \AA$ in crystal structures, while the ionic radii 
of $\mathrm{Co}$ (II) in 5-coordinate complexes are typically around $0.67 \AA$ in crystal structures [86]. The ionic radii of the metals in our gas-phase complexes are probably not exactly the same as they would be in the solid phase, but the trend should be the same.

\section{Conclusions}

Previous I-M reactions of doubly-charged metal complexes of first-row transition metals demonstrated that reactions with certain neutrals allowed the coordination number to be ascertained $[54,56]$. The previous studies, however, were essentially limited to ligands that only had nitrogen donor groups. The present work not only shows that acetonitrile can be used as a titrant to determine coordination number but also shows that the coordination numbers of complexes with donor groups other than nitrogens can be effectively determined using I-M reactions. The main stipulation to this observation is that the ligand must have donor groups that bind strongly to the metal (i.e., strong $\sigma$ interactions). In the reactions of metal complexes that contain weakly binding functional groups such as thiophene, furan, or benzene, acetonitrile seems to displace these weakly bound groups, making an unambiguous determination of coordination number difficult.

The reactions of acetonitrile with a series of Co(II) and $\mathrm{Cu}(\mathrm{II})$ complexes having varied coordination spheres also clearly demonstrate that the donor atoms in the coordination sphere can dramatically affect reactivity. The results generally show that the more nitrogen donor atoms in the coordination sphere the less reactive the complex is, and the more sulfur and oxygen donor atoms present the more reactive the complex is. The equilibrium constant for the addition of one acetonitrile is one of the means of gauging these reactivity differences. A lower equilibrium constant is indicative of weaker acetonitrile binding, which in turn is a measure of how much electron density is donated to the metal center by the ligand sphere. According to the HSAB principle, borderline acids like $\mathrm{Co}(\mathrm{II})$ and $\mathrm{Cu}(\mathrm{II})$ prefer borderline bases such as pyridine and imidazole groups over either hard bases like THF or soft bases like thioethers. The preference for nitrogen donor groups allows more extensive donation of electron density to $\mathrm{Co}(\mathrm{II})$ and $\mathrm{Cu}(\mathrm{II})$, thus explaining the reduced reactivity of the complexes with more nitrogen donors.

The presence of strong donating groups such as pyridine and imidazole seems to also have another noticeable effect on the reactivity of certain complexes. In complexes that contain a pyridine or imidazole group and a thioether group, the resultant complex reactivity is lower than expected. This result suggests that the strong nitrogen donor group provides enough electron density to increase the polarizability of the metal center, thus making the metal a softer acid. Consequently, the binding of the soft base thioether is enhanced, reducing the overall reactivity of the com- plex. Current studies are underway to assess the generality of this effect.

Finally, because our data indicates that different coordination spheres can dramatically impact the reactivity of their metal complexes, I-M reactions may provide a means of gathering coordination structure information in an analytically useful manner. Both Tables 4 and 5 show that the reaction rate constants and the equilibrium constants are significantly different for most of the metal-ligand complexes. With very defined and controlled conditions the extent of reagent gas addition after a given reaction time could be used to identify the functional groups involved in coordination. Such identification would require construction of a database of reaction rate constants or equilibrium constants for complexes with different coordination spheres. It would also require a better understanding of the factors affecting the gas-phase reactivity of metal complexes in general. Work toward these goals is underway in our laboratory. Successful development of a technique based on mass spectrometry that could provide coordination structure information would be useful for metal complexes that are present at low levels or as mixtures in environmental and biological systems.

\section{Acknowledgments}

MYC would like to thank the Schering-Plough Research Institute for a summer research fellowship. This work was sponsored in part by the Office of Naval Research under Award No. N000140010796.

\section{References}

1. Armentrout, P. B.; Baer, T. J. Phys. Chem. 1996, 100, 1286612877.

2. Fornarini, S. Mass Spectrom. Rev. 1996, 15, 365-389.

3. Born, M.; Ingemann, S.; Nibbering, N. M. M. Mass Spectrom. Rev. 1997, 16, 181-200.

4. Stone, J. A. Mass Spectrom. Rev. 1997, 16, 25-49.

5. Gross, M. L.; Lin, P. H.; Franklin, S. J. Anal. Chem. 1972, 44, 974-978.

6. Suckau, D.; Shi, Y.; Beu, S. C.; Senko, M. W.; Quinn, J. P. Wampler, F. M., III;; McLafferty, F. W. Proc. Natl. Acad. Sci. U.S.A. 1993, 90, 790-793.

7. Brodbelt, J. S. Mass Spectrom. Rev. 1997, 16, 91-110.

8. Green, M. K.; Lebrilla, C. B. Mass Spectrom. Rev. 1997, 16, 53-71.

9. Feng, W. Y.; Gronert, S. Annu. Rep. Prog. Chem. Sect. B. 1999, 95, 349-372.

10. Rodgers, M. T.; Armentrout, P. B. Mass Spectrom. Rev. 2000, 19, 215-247, and references therein.

11. Alvarez, E. J.; Wu, H.-F.; Liou, C.-C.; Brodbelt, J. J. Am. Chem. Soc. 1996, 118, 9131-9138.

12. Shen, J.; Brodbelt, J. S. Int. J. Mass Spectrom. Ion Processes 1998, $176,39-61$.

13. Alvarez, E. J.; Vartanian, V. H.; Brodbelt, J. S. J. Am. Soc. Mass Spectrom. 1997, 8, 620-629.

14. Shen, J.; Brodbelt, J. J. Am. Soc. Mass Spectrom. 1999, 10, 126-135.

15. Alvarez, E. J.; Vartanian, V. H.; Brodbelt, J. S. Anal. Chem. 1997, 69, 1147-1155. 
16. Hopfgartner, G.; Piguet, C.; Henion, J. D. J. Am. Soc. Mass Spectrom. 1994, 5, 748-756.

17. Gatlin, C. L.; Turecek, F.; Vaisar, T. J. Am. Chem. Soc. 1995, 117, 3637-3638.

18. Gatlin, C. L.; Turecek, F.; Vaisar, T. J. Mass Spectrom. 1995, 30, 1605-1616

19. Gatlin, C. L.; Turecek, F.; Vaisar, T. J. Mass Spectrom. 1995, 30, 1617-1627.

20. Kohler, M.; Leary, J. A. J. Am. Soc. Mass Spectrom. 1997, 8, 1124-1133.

21. Sible, E. M.; Brimmer, S. P.; Leary, J. A. J. Am. Soc. Mass Spectrom. 1997, 8, 32-42.

22. Henderson, W.; Fawcett, J.; Kemmitt, R. D. W.; McKenna, P.; Russell, D. R. Polyhedron 1997, 16, 2455-2463.

23. Domingues, M. R. M.; Nemirovskiy, O. V.; Marques, M. G. O. S.; Neves, M. G.; Cavaleiro, J. A. S.; Ferrer-Correia, A. J.; Gross, M. L. J. Am. Soc. Mass Spectrom. 1998, 9, 767-774.

24. Chu, I. K.; Lau, T. C.; Siu, K. M. W. J. Mass Spectrom. 1998, 33, 811-818.

25. Shen, J.; Brodbelt, J. S. Analyst 2000, 125, 641-650.

26. Desaire, H.; Beyer, M. K.; Leary, J. A. J. Am. Soc. Mass Spectrom. 2001, 12, 528-536.

27. Hu, P.; Gross, M. L. J. Am. Chem. Soc. 1993, 115, 8821-8828.

28. Reiter, A.; Adams, J.; Zhao, H. J. Am. Chem. Soc. 1994, 116, 7827-7838

29. Loo, J. A.; Hu, P.; Smith, R. D. J. Am. Soc. Mass Spectrom. 1994, 5, 959-965.

30. Hu, P.; Loo, J. A. J. Am. Chem. Soc. 1995, 117, 11314-11319.

31. $\mathrm{Hu}$, P.; Sorensen, C.; Gross, M. L. J. Am. Soc. Mass Spectrom. 1995, 6, 1079-1085.

32. Nemirovskiy, O. V.; Gross, M. L. J. Am. Soc. Mass Spectrom. 1996, 7, 977-980.

33. Li, H.; Siu, K. W. M.; Guevremont, R. Le; Blanc, J. C. Y. J. Am. Soc. Mass Spectrom. 1997, 8, 781-792.

34. Nemirovskiy, O. V.; Gross, M. L. J. Am. Soc. Mass Spectrom. 1998, 9, 1285-1292.

35. Russell, D. H. Gas Phase Inorganic Chemistry. Plenum Press: New York, 1989.

36. Eller, K.; Schwarz, H. Chem. Rev. 1991, 91, 1121-1177.

37. Fisher, K. J. Prog. Inorg. Chem. 2001, 50, 343-432.

38. Schroder, D.; Schwarz, H. Angew. Chem. Int. Edit. 1995, 34, 1973-1995.

39. Baranov, V. Becker, H.; Bohme, D. K. J. Phys. Chem. A 1997, 101, 5137-5147.

40. Russo, N.; Salahub, D. R.; NATO Science Series. Metal-Ligand Interactions in Chemistry, Physics, and Biology, Vol DXLVI. Kluwer Academic Publishers: Dordrecht, The Netherlands, 1998.

41. Armentrout, P. B. Acc. Chem. Res. 1995, 28, 430-436.

42. Walker, N. R.; Firth, S.; Stace, A. J. J. Am. Chem. Soc. 1997, 119, 10239-10240.

43. Walker, N. R.; Firth, S.; Stace, A. J. Chem. Phys. Lett. 1998, 292, 125-132.

44. Jayaweera, P.; Blades, A. T.; Ikonomou, M. G.; Kebarle, P. J. Am. Chem. Soc. 1990, 112, 2452-2454.

45. Blades, A. T.; Jayaweera, P.; Ikonomou, M. G.; Kebarle, P. J. Chem. Phys. 1990, 92, 5900-5906.

46. Rodriguez-Cruz, S. E.; Jockusch, R. A.; Williams, E. R. J. Am. Chem. Soc. 1998, 120, 5842-5843.

47. Peschke, M.; Blades, A. T.; Kebarle, P. J. Am. Chem. Soc. 2000, 122, 10440-10449.

48. Walker, N. R.; Wright, R. R.; Barran, P. E.; Murrell, J. M.; Stace, A. J. J. Am. Chem. Soc. 2001, 123, 4223-4227.

49. Stace, A. J. Phys. Chem. Chem. Phys. 2001, 3, 1935-1941.
50. Burns, T. D.; Spence, T. G.; Mooney, M. A.; Posey, L. A. Chem. Phys. Lett. 1996, 258, 669-679.

51. Spence, T. G.; Burns, T. D.; Guckenberger, G. B.; Posey, L. A. J. Phys. Chem. A 1997, 101, 1081-1092.

52. Andersen, U. N.; Bojesen, G. Int. J. Mass Spectrom. Ion Processes 1996, 153, 1-7.

53. Molina-Svendsen, H.; Bojesen, G.; McKenzie, C. J. Inorg. Chem. 1998, 37, 1981-1983.

54. Vachet, R. W.; Hartman, J. A. R.; Callahan, J. H. J. Mass Spectrom. 1998, 33, 1209-1225.

55. Nielsen, S. B.; Bojesen, G. Chem. Commun. 1998, 613-614.

56. Vachet, R. W.; Hartman, J. R.; Gertner, J. W.; Callahan, J. H. Int. J. Mass Spectrom. 2001, 204, 101-112.

57. Zhang, X.; Cassady, C. J. J. Am. Soc. Mass Spectrom. 1996, 7, 1211-1218.

58. Harris, W. R.; Murase, I.; Timmons, J. H.; Martell, A. E. Inorg. Chem. 1978, 17, 889-894.

59. Timmons, J. H.; Harris, W. R.; Murase, I.; Martell, A. E. Inorg. Chem. 1978, 17, 2192-2197.

60. Bernardo, M. A.; Guerrero, J. A.; Garcia-Espana, E.; Luis, S. V.; Llinares, J. M.; Pina, F.; Ramirez, J. A.; Soriano, C. J. Chem. Soc. Perkins Trans. 2 1996, 2335-2342.

61. Shen, N. Z.; Pope, R. M.; Dearden, D. V. Int. J. Mass Spectrom. 2000, 196, 639-652.

62. Bauschlicher, C. W.; Langhoff, S. R.; Partridge, H. J. Chem. Phys. 1991, 94, 2068-2072.

63. Nanayakkara, V. K.; Freiser, B. S. J. Mass Spectrom. 1997, 32, 475-482.

64. Reynolds, M. A.; Guzei, I. A.; Logsdon, B. C. Thomas L. M.; Jacobson, R. A.; Angelici, R. J. Organometallics 1999, 18, 40754081.

65. Liu, S. Lucas C. R.; Newlands, M. J.; Charland, J. P. Inorg. Chem. 1990, 29, 4380-4385.

66. Lucas, C. R.; Liu, S.; Thompson, L. K. Inorg. Chem. 1990, 29, 85-88.

67. Angelici, R. J. Organometallics 2001, 20, 1259-1275.

68. Sargent, A. L.; Titus, E. P.; Riordan, C. G.; Rheingold, A. L.; Ge, P. Inorg. Chem. 1996, 35, 7095-7101.

69. Jacobson, D. B.; Bakhtiar, R. J. Am Soc. Mass Spectrom. 1996, 7, 938-952.

70. Kershner, D. L.; Basolo, F. Coord. Chem. Rev. 1987, 79, 279-292.

71. Chaudret, B.; Jalon, F. A. J. Chem. Soc. Chem. Commun. 1988, 711-713.

72. Su, T.; Bowers, M. T. Int. J. Mass Spectrom. Ion Phys. 1973, 12, 347-356.

73. Su, T.; Bowers, M. T. J. Chem. Phys. 1973, 58, 3027-3037.

74. Barker, R. A.; Ridge, D. P. J. Chem. Phys. 1976, 64, 4411-4416.

75. Celli, F.; Weddle, G.; Ridge, D. P. J. Chem. Phys. 1980, 73, 801-812.

76. Su, T; Chesnavich, W. J. J. Chem. Phys. 1982, 76, 5183-5185.

77. Cassady, C. J. Wronka J.; Laukien F. H. Rapid Commum. Mass Spectrom. 1994, 8, 394-400.

78. Hettich, R. L.; Jackson, T. C.; Stanko, E. M.; Freiser, B. S. J. Am. Chem. Soc. 1986, 108, 5086-5093.

79. Meyer, F.; Khan, F. A.; Armentrout, P. B. J. Am. Chem. Soc. 1995, 117, 9740-9748.

80. Hartman, J. R.; Vachet, R. W.; Pearson, W.; Wheat, R. J.; Callahan, J. H., in preparation.

81. Hancock, R. D.; Martell, A. E. Chem. Rev. 1989, 89, 1875-1914.

82. Pearson, R. G. J. Am. Chem. Soc. 1963, 85, 3533.

83. Griesser, R.; Sigel, H. Inorg. Chem. 1970, 9, 1238-1243.

84. Griesser, R.; Sigel, H. Inorg. Chem. 1971, 10, 2229.

85. Sigel, H.; Huber, P. R.; Griesser, R.; Prijs, B. Inorg. Chem. 1973, 12, 1198-1200.

86. Shannon, R. D. Acta Cryst. 1976, A32, 751-767. 